Vietnam Journal of Mechanics, NCST of Vietnam Vol. 22, 2000, No 2 (124-128)

Short Communication

\title{
DYNAMIC AMPLIFICATION FACTOR IN THE PROBLEM OF INCLINED IMPACT
}

\author{
PHAN VAN KHOI \\ Institute of Mechanics, 264 Doi Can, Hanoi
}

\begin{abstract}
The purpose of this article is to investigate an advanced method for presentation of the impact problem between the rigid body and the elastic beam.

Results show that this method gives a solution which is more general than the solutions illustrated in the textbook of Strength of Materials. The developed formulations may expand the applied sphere of the dynamic amplification factor (DAF), $k_{d}$, as in the case of driving inclined piles.
\end{abstract}

\section{Formulation of the problem}

In the ordinary textbooks of Strength of Materials, the problem of impact is presented with its two particular cases:

- impact body with the weight of $Q$ moves in the vertical direction (vertical impact, Fig. $1 \mathrm{a}$ and $1 \mathrm{~b}$ ) and

- impact body moves in the horizontal direction (horizontal impact, Fig.1c and 1d), where the beams may be located horizontally or vertically only.

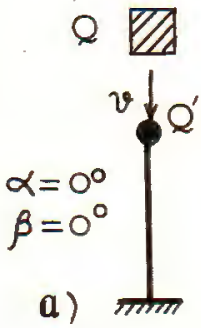

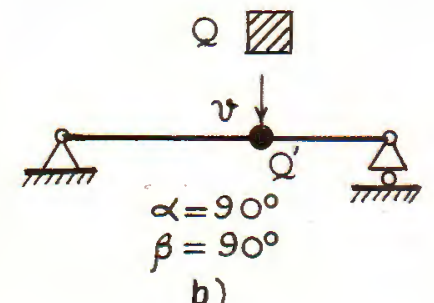

b)

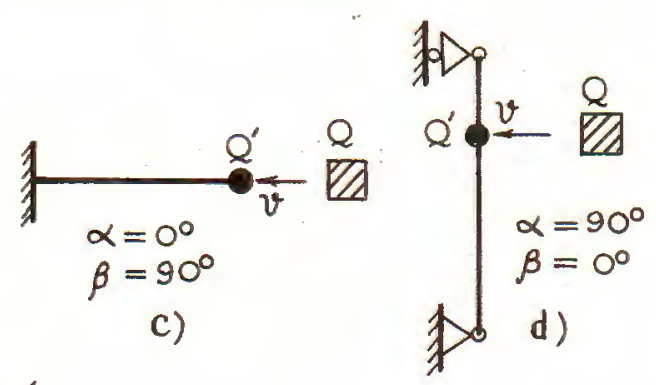

Fig. 1

It is obvious that the obtained results may not be applied to general cases, which are often encountered in practice, when the impact body moves in arbitrary direction and the beam axis is inclined at an arbitrary angle.

On the other hand, the presentation of two particular cases of a problem with 
the same principle is not advisable according to teaching methodology.

Hence, the above problem of impact may be formulated generally as follows:

A rigid body of the mass $Q / g$ impinges on the beam with the velocity $v$, where $g$ is the acceleration of gravity. At the impact point in the beam there may already exist another body of the mass $Q^{\prime} / g$. This mass may also be a reduced mass of the beam at the impact point, Fig. 2 . Find the dynamic amplification factor, $k_{d}$.

\section{Solutions}

We denote

$\alpha$ - angle between the moving direction of the body $Q$ and the beam axis, $x$;

$\beta$ - angle between the vertical line and the beam axis.

A system consists of both bodies of the mass $\left(Q+Q^{\prime}\right) / g$, which are assumed to be joined firmly to one another. The system moves in the potential force field during the impact process.

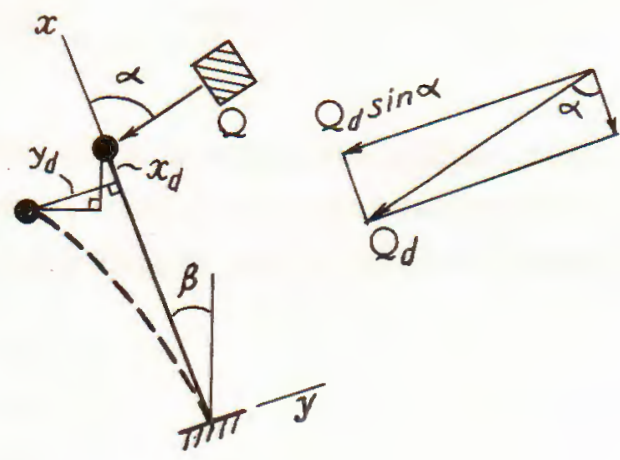

Let $v_{0}$ - system velocity just at the beginning of impact; $x_{d}$ and $y_{d}$ - axial and bending displacements respectively of the impact point, due to the dynamic force, $Q_{d}$.

Keeping all known assumptions, according to the theorem of energy conservation we get

$$
\begin{aligned}
\frac{1}{2}\left(\frac{Q+Q^{\prime}}{g}\right) v_{0}^{2}= & -\left(Q+Q^{\prime}\right)\left(y_{d}^{2}+x_{d}^{2}\right)^{1 / 2} \cos (\alpha-\beta)+Q^{\prime}\left(y_{d}^{2}+x_{d}^{2}\right)^{1 / 2} \cos (\alpha-\beta) \\
& +\frac{Q_{d} \cos \alpha}{2} x_{d}+\frac{Q_{d} \sin \alpha}{2} y_{d}
\end{aligned}
$$

where the left hand side of the equation (2.1) is the kinetic energy of the system at the beginning of impact, the first term on the right hand side of the equation (2.1) is the decrease of potential energy of the system, and the remaining terms are the elastic works of the beam under the action of the dynamic load, $Q_{d}$.

The system velocity $v_{0}$ may be determined by the velocity $v$ of the body $Q$ just before impact, by means of the momentum conservation theorem:

$$
v_{0}=\frac{Q}{Q+Q^{\prime}} v
$$


Therefore, the left hand side of the equation (2.1) becomes

$$
\frac{1}{2}\left(\frac{Q+Q^{\prime}}{g}\right) v_{0}^{2}=\frac{Q v^{2}}{2 g\left(1+\frac{Q^{\prime}}{Q}\right)}
$$

Equation (2.1) can be rewritten as

$$
\begin{aligned}
\frac{Q}{2 g\left(1+\frac{Q^{\prime}}{Q}\right)} v^{2}= & \left.-\left(Q+Q^{\prime}\right)\left(y_{d}^{2}+x_{d}^{2}\right)\right)^{1 / 2} \cos (\alpha-\beta)+Q^{\prime}\left(y_{d}^{2}+x_{d}^{2}\right)^{1 / 2} \cos (\alpha-\beta) \\
& +\frac{Q_{d} \cos \alpha}{2} x_{d}+\frac{Q_{d} \sin \alpha}{2} y_{d}
\end{aligned}
$$

If $x_{s}$ and $y_{s}$ are denoted as the displacements (axial and bending, respectively) of the beam at the impact point, when the beam is subjected statically to a force of value $Q$ acting in the impact direction, it yields

$$
\left.\begin{array}{rl}
x_{d} & =x_{s} k_{d} \\
y_{d} & =y_{s} k_{d} \\
Q_{d} & =Q k_{d}
\end{array}\right\}
$$

The values of $x_{s}$ and $y_{s}$ are determined easily by means of the statical analysis of the given structure subjected to the force of $Q$.

After some substitutions, the equation (2.4) becomes a quadratic equation of $k_{d}$; that is

$$
\frac{1}{2}\left(x_{s} \cos \alpha+y_{s} \sin \alpha\right) k_{d}^{2}-k_{d}\left(y_{s}^{2}+x_{s}^{2}\right)^{1 / 2} \cos (\alpha-\beta)-\frac{v^{2}}{2 g\left(1+\frac{Q^{\prime}}{Q}\right)}=0 .
$$

The positive solution of this equation is the required dynamic amplification factor, $k_{d}$ :

$$
\begin{aligned}
k_{d}= & \frac{1}{x_{s} \cos \alpha+y_{s} \sin \alpha}\left\{\left(x_{s}^{2}+y_{s}^{2}\right)^{1 / 2} \cos (\alpha-\beta)\right. \\
& \left.+\left[\left(x_{s}^{2}+y_{s}^{2}\right) \cos ^{2}(\alpha-\beta)+\left(x_{s} \cos \alpha+y_{s} \sin \alpha\right) \frac{v^{2}}{g\left(1+\frac{Q^{\prime}}{Q}\right)}\right]^{1 / 2}\right\} .
\end{aligned}
$$

\section{Studying particular cases}

Some particular cases may be considered as follows: 
3.1 $\alpha=0^{\circ}$ : If the impact direction coincides with the direction of the beam axis, as in Fig. 3a, then

$$
\cos (\alpha-\beta)=\cos \beta ; \quad y_{s}=0
$$

Therefore

$$
k_{d}=\cos \beta+\left[\cos ^{2} \beta+\frac{v^{2}}{g x_{s}\left(1+\frac{Q^{\prime}}{Q}\right)}\right]^{1 / 2} .
$$

3.2 $\alpha=\beta$ : If the impact direction is vertical and the beam axis is inclined arbitrarily, as in Fig. 3b, the equation (2.7) can be expressed as

$$
\begin{aligned}
k_{d}= & \frac{1}{x_{s} \cos \beta+y_{s} \sin \beta}\left\{\left(x_{s}^{2}+y_{s}^{2}\right)\right. \\
& \left.+\left[\left(x_{s}^{2}+y_{s}^{2}\right)+\left(x_{s} \cos \beta+y_{s} \sin \beta\right) \frac{v^{2}}{g\left(1+\frac{Q^{\prime}}{Q}\right)}\right]^{1 / 2}\right\}
\end{aligned}
$$

3.3 $\alpha=90^{\circ}+\beta$ : If the impact direction is horizontal and the beam axis is inclined arbitrarily, as in Fig. 3c, the DAF becomes

$$
k_{d}=\frac{v}{\left[g\left(1+\frac{Q^{\prime}}{Q}\right)\left(y_{s} \cos \beta-x_{s} \sin \beta\right)\right]^{1 / 2}} .
$$
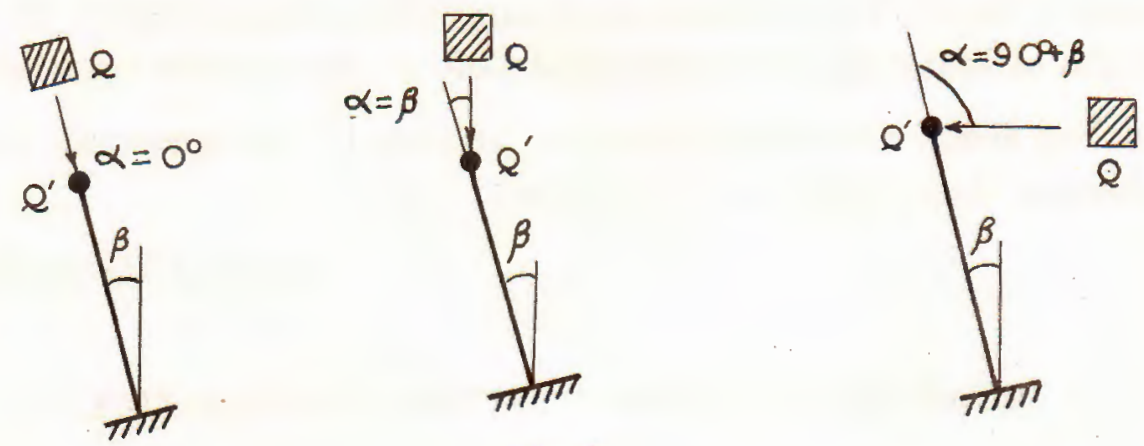

Fig. 3

3.4 If a) $\alpha=0^{\circ}$ and $\beta=0^{\circ}$ or b) $\beta,=90^{\circ}$ and $\alpha=90^{\circ}$ (vertical impact), the $\mathrm{DAF}$ is

$$
k_{d}=1+\left[1+\frac{v^{2}}{g \Delta_{s}\left(1+\frac{Q^{\prime}}{Q}\right)}\right]^{1 / 2},
$$

where $\Delta_{s}=x_{s}$ in the case a) and $\Delta_{s}=y_{s}$ in the case b), as in Fig. 1a and $1 \mathrm{~b}$. 
3.5 If a) $\alpha=0^{\circ}$ and $\beta=90^{\circ}$ or b) $\alpha=90^{\circ}$ and $\beta=0^{\circ}$, we get

$$
k_{d}=\frac{v}{\left[g \Delta_{s}\left(1+\frac{Q^{\prime}}{Q}\right)\right]^{1 / 2}},
$$

where $\Delta_{s}$ is denoted as in 3.4 , as in Fig. 1c and 1d respectively.

3.6 If the body $Q$ falls freely from the height of $H$, the velocity of the body just before impact will be

$$
v=\sqrt{2 g H}
$$

\section{Conclusion}

The dynamic amplification factor, $k_{d}$, obtained in the equation (2.7) is the general solution for the problem of the inclined impact. The equations (3.1), (3.2) and (3.3) can be applied to the cases of driving inclined piles in practice. The equations (3.4) and (3.5) are the particular cases of the solution (2.7) and coincide with the solutions obtained in the textbooks of Strength of Materials.

Acknowledgment. The author is grateful to the Council for Natural Sciences of Vietnam for financial support.

\section{REFERENCES}

1. Johnson W. Impact Strength of Materials. Edward Arnold 1972.

2. Nguyen $Y$ To, Le Minh Khanh, Le Quang Minh, Nguyen Khai, Vu Dinh Lai. Strength of Materials. University and College, Hanoi 1970 (in Vienamese).

3. Phan Van Khoi. Structural Analysis, Volume 1-Fundamental. Institute of Mechanics, Ḣanoi 1998 (in Vietnamese).

Received March 23, 2000

HỆ SỐ ĐộNG LỰC TRONG BÀI TOÁN VA CHẠM XIÊN

Một cách phát biểu và giải bài toán va chạm giữa một vật cứng với một thanh đàn hồi được đề xuất trong bài báo này, trong đó phương va chạm và phương của trục thanh nghiêng góc bất kỳ.

Kết quả chỉ ra rằng nghiệm của bài toán này là tồng quát hơn, và những nghiệm nhận được trong các giáo trình Sức bền vật liệu là trường hợp riêng. Kết quá cũng làm mở rộng phạm vi ưng dụng của hệ số động khi va chạm, chẳng hạn khi đóng cọc xiên. 